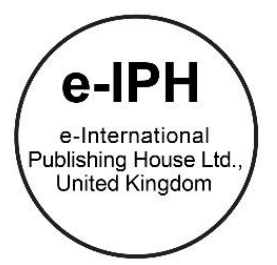

\title{
The Determinant of Consumers' Socio-Economic Attributes on their Choices of Environmental Friendly Furniture Style
}

\author{
Karuna Kwangsawat ${ }^{1 *}$, Yanin Rugwongwan ${ }^{2}$ \\ ${ }^{1}$ Arch D. Student, ${ }^{2}$ Asst. Prof. PhD Program, School of Interior Architecture, \\ Faculty of Architecture, \\ King Mongkut's Institute of Technology Ladkrabang (KMITL), Thailand. \\ Kwangsawath@yahoo.com \\ Tel: +66-804-145426
}

\begin{abstract}
This article presents the determinant of consumers' socio-economic including personality, attitudes, lifestyle and the physical characteristics of the residence. That determines the consumer's demand for environmentally friendly furniture. This is a test of the demand for different types of furniture. According to economic conditions consumer society. The research found that overall style of furniture requirements. The consumers demand modern style furniture, western style, use natural materials to produce, high technology in production and the furniture is cool shade is moderate. The design should take into account the socio-economic conditions of each consumer group. To serve as guidelines for the environmentally friendly design furniture that is suitable to the demand of consumers.
\end{abstract}

Keywords: Furniture Design, Environmental Friendly Furniture, Consumers' Socio-Economic, Attributes

eISSN: 2398-4287@ 2017. The Authors. Published for AMER ABRA by e-International Publishing House, Ltd., UK. This is an open access article under the CC BYNCND license (http://creativecommons.org/licenses/by-nc-nd/4.0/). Peer-review under responsibility of AMER (Association of Malaysian Environment-Behaviour Researchers), ABRA (Association of Behavioural Researchers on Asians) and cE-Bs (Centre for Environment-Behaviour Studies), Faculty of Architecture, Planning \& Surveying, Universiti Teknologi MARA, Malaysia.

https://doi.org/10.21834/e-bpj.v2i6.950

\subsection{Introduction}

The furniture industry is supported and promoted for the local market and exports in Thailand. (SMEs, 2014) But not developed a new design. That is recognised in the market at Thailand and global markets. Using the appropriate materials and manufacturing processes. The ability to combine materials. To produce furniture according to the popularity of each era. This is a technological distortion issue. Shortages of the skilled labour force. And has low production technology. So, it is necessary to develop the more efficient design.

Later adopted the design method for the environment. (Design for Environment: DfE) Used in the design process, which is extremely important for product design. And modified to a greater force for management products and services on the environment. Especially in Northern European countries, Japan and the United States used as a product regulation. Some companies have adopted concepts in design and product improvement. As a result, these companies become the market leader in the highly competitive. (Brezet J., 1997) To be able to design more according to market demand. Which currently focuses on the green consumer and green market. The consumer can demand that the manufacturer pay attention to the environment. The importance of buying products and services that minimize environmental impact. Manufacturer and entrepreneur must pay attention to the green consumer. There are many factors that affect consumer buying behaviour include demographics, self- concept, knowledge and values. The most influential factors are: demographic, or the social-economic of consumers include gen, age, education, occupation and income. (Consultants of Technology Co., 2556) The difference in the socio-economic conditions of the consumers is the factor that can determine the demands of the style of furniture to suit and demand response of consumers. (Henlen Lewis and John Gertsakis whit Tim Grant, 2001) This article aims to

eISSN: 2398-4287@ 2017. The Authors. Published for AMER ABRA by e-International Publishing House, Ltd., UK. This is an open access article under the CC BYNCND license (http://creativecommons.org/licenses/by-nc-nd/4.0/). Peer-review under responsibility of AMER (Association of Malaysian Environment-Behaviour Researchers), ABRA (Association of Behavioural Researchers on Asians) and cE-Bs (Centre for Environment-Behaviour Studies), Faculty of Architecture, Planning \& Surveying, Universiti Teknologi MARA, Malaysia.

https://doi.org/10.21834/e-bpj.v2i6.950 
find design guidelines for furniture that can reduce the environmental impact. Focus on finding the factors that influence the demand for environmentally friendly furniture of consumers with different socio-economic status. This research is aim to the designer can use the design guidelines and develop environmentally friendly furniture that demand response of the consumer market and the furniture is less impact on the environment.

\subsection{Literature Review}

Socio-economic factors of consumers have an impact on the choice of environmentally friendly furniture. This study that the researcher wants to find the style of environmentally-friendly furniture that is suitable for present socio-economic conditions. To develop environmentally friendly furniture suitable to the market. The researcher studied the papers and research that consistent with objectives of the research. Include the design of environmentally friendly furniture.

The furniture industry is paying more attention to the environment. By focusing on the production. In the office furniture industry, industrial designers and facility managers are aware of the environmental impact caused by the production. (Mohamad T. Araji, 2013) The design issues related to furniture are two main issues: the functional and design objectives for the environment. The furniture must be productive and practical. And it is the market's demand. The essence of the design for the environment. It must be considered throughout the life cycle of the product in the design process to ensure that it will help reduce environmental problems. To move towards elimination or reduce the most severe environmental problems. (Matthew A. Cole, 2007)

\subsection{Material Selection}

Environmentally friendly materials should be selected. There are methods for recycling or consistent with disassembly reduce the amount of material to the minimum with emphasis on function and usability remains. And the quality of the aesthetics or standards applied. (Hayles, 2015) As follows:

-Contains recyclable materials

-Do not cause toxic or dangerous.

-From renewable sources.

-Can be recycled easily.

-low power consumption.

-Does not cause indoor air quality to be toxic or Sick building syndrome.

-No ozone depletion.

-Reduce variety of material types and easy to recycle.

-No potential colour, texture, or visible object is obscured. Key points from using recycled materials.

-Use sustainably managed forest materials.

\subsection{Production}

Maximizing productivity and minimizing impact:

- Reduce the number of components and components.

- Removal and reduction of gemstones. Minimal waste material.

- Reduce variety of material types.

- Include functional functions together.

-To reduce the hassle and number of components.

- Use low impact materials and use clean production processes.

- Avoid the use of adhesives that require solvent coatings. And additives containing heavy metals. (Matthew A. Cole, 2007)

\subsection{Use}

Normally the uses procedure has low environmental impact. However, the following should be considered:

-pay attention to materials and quality, feel, colour, touch, surface design.

-The innovation It is a healthy work area that is good for the workplace.

-Furniture must be easy to modify and durable.

-Do not obsolete and must be disposed of with no service life.

-And most importantly is Danger to human health It involves the release of chemicals such as formaldehyde. Nitrogen dioxide Chlorofluorocarbons (CFCs) and volatile organic compounds (VOCs) are another form of air pollution (off-gassing), which affects health and affects the effectiveness of poor employee perform.

\subsection{Avoiding waste and reusing resources.}

The problems that arise during production and disposal are disposal procedures or end of life. The remains of furniture a major issue that results in the amount of furniture that needs to be shovelled or the coating and the decoration of heavy metal is a component. It causes contamination around landfills, and there is also the cost of energy and energy transfer from moving the furniture to the landfill, so reusable materials should be selected. Or go through a new process. Durable material is easier to recycle. (Hayles, 2015) It is a way to pull a product out of the waste cycle. The importance of the purpose of eco-economic design is the design for durability. Design 
for disassembly. The design for bruising and regeneration. Design for recycling Safe disposal design. (Henlen Lewis and John Gertsakis whit Tim Grant, 2001)

\subsubsection{Design for durability Can be increased by}

-Identify and eliminate key weaknesses in the design.

-Especially the parts for use.

-The design must be compatible with normal conditions and misuse.

-Can be easily repaired or serviced.

-Product design should be upgraded. (upgradability)

\subsubsection{Design to disassemble}

Remember to make the material easy to separate parts for recycling. It should be repaired and upgraded to a new one.

-The number of components that are the least fragmented.

-Avoid glue. Metal clamps and screws To use the method by push, hook. Bolt snap fit (Click)

-Tighten with materials that are compatible with parts. Connected Points and items Easily accessible Removable hand

-Block Design

-In-mold identification on resin parts. To distinguish plastics (from ISO 11469 (ISO 2000))

-The minimum material type.

-Components that cannot be recycled are easy to remove and dispose of.

-The highest priced parts are easily accessible.

-Removing and assembling can be done with simple tools. This makes removing and assembling the smallest possible.

-Parts Get as standard as you can.

-Fix in and fastener. Easy to separate pieces to avoid damage.

\subsubsection{Design for Reproduction and Reproduction}

The low environmental impact is mostly a reusable product. Which must be considered, as well as the life cycle in the design process. Should do the following:

\subsubsection{Design for Material Recycling}

A second product can be used.

- Use the least amount of material types. And only 2-3 types, although the volume is high because it can be recycled better than using 4-5 types, less.

- There should be a code or symbol that can identify the type of material.

- When disassembled. Should be separated to be kind. Identify species for fast, safe, unmixed.

- Avoid contamination of metal in plastic.

- Avoid using laminate and composite materials.

- Use a tensile strap to prevent contamination of cross-type materials.

- Avoid using an adhesive that is different from the material to be welded together. To avoid contamination.

- Choose duplicate materials at every stage of design as possible.

\subsubsection{Safe disposal design}

Observe label precautions for disposal. How to bind gas contaminants or identify toxic substances. Include contact information for safe disposal. The most important thing is not to use substances or ingredients that cause pollution problems.

\subsection{System-wide issues}

Environmentally friendly products should be a unified where environmentally friendly products. Need an environmentally friendly system. In the following activities:

\subsubsection{Integrated Care and Recovery}

Manufacturers must be emphasized of environmental policies and regulations. The current is more concentrated. The manufacturer must remove the product. At the end of its useful life must be called back to eliminate. Responsibility is more than sales of the showroom. Warranty and service agreement product stewardship and extended product responsibility for such a method is called "product take-back". (Ming-Chuan Chiu, 2012)

\subsection{Methodology}

\subsection{The scope of education}




\section{Scope of variables studied}

1.Type of furniture: Table furniture represents the furniture used in the study.

2.Create a model of table. Based on the issue of environmentally friendly furniture design. The issue is as follows furniture style, materials used in the manufacture, technology used in the manufacture and colour of furniture.

\section{This research had to break down data collecting to study a 2 step.}

1.The socio-economic characteristics of consumers. Using Questionnaire.

2.Characterization of furniture, such as the style of furniture. Using Questionnaire and Stimuli.

\subsection{Tool validity.}

Apply the model of table furniture produced by modelling the issue of eco-friendly furniture design for three furniture specialists. To test the clarity of the tool, it is possible to communicate the issues of environmentally friendly furniture design. They can communicate the issues of eco-friendly furniture design.

\subsection{Data Collection}

Factors affecting the presentation of environmentally friendly furniture, ie, socio-economic characteristics of consumers. For this research is in the pilot study period. Because the furniture is diverse, to find the representative of the furniture to be used in the questionnaire by 50 samples were selected for the selection of furniture. The table furniture was the first furniture purchased by the sample, representing the furniture used as a research tool.

The sample of this research will not divide the sample of furniture purchased or do not purchased furniture to get the information of both those who make a purchase and not to buy. Using a tool to create stimuli used in the questionnaire, using a voluntary sample group. The questionnaire was divided into two peoples. To be able to take care of the respondents completely. It took 30 minutes to collect the questionnaire. The place to collect the questionnaire was a shopping mall with a furniture showroom.

\subsection{Research Methodology Tools}

The questionnaire used a model of furniture. Determine the style of the environmentally friendly furniture of the sample. The comparable with five levels of popularity.

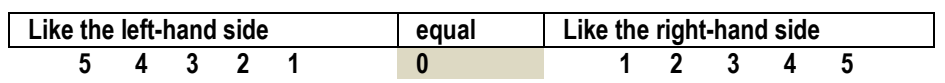

Like the left-hand side select in the 1-5 number field on the left-hand side. Like the right-hand side select in the 1-5 number field on the right-hand side. Like both pictures are equal. Choice in the 0 number.

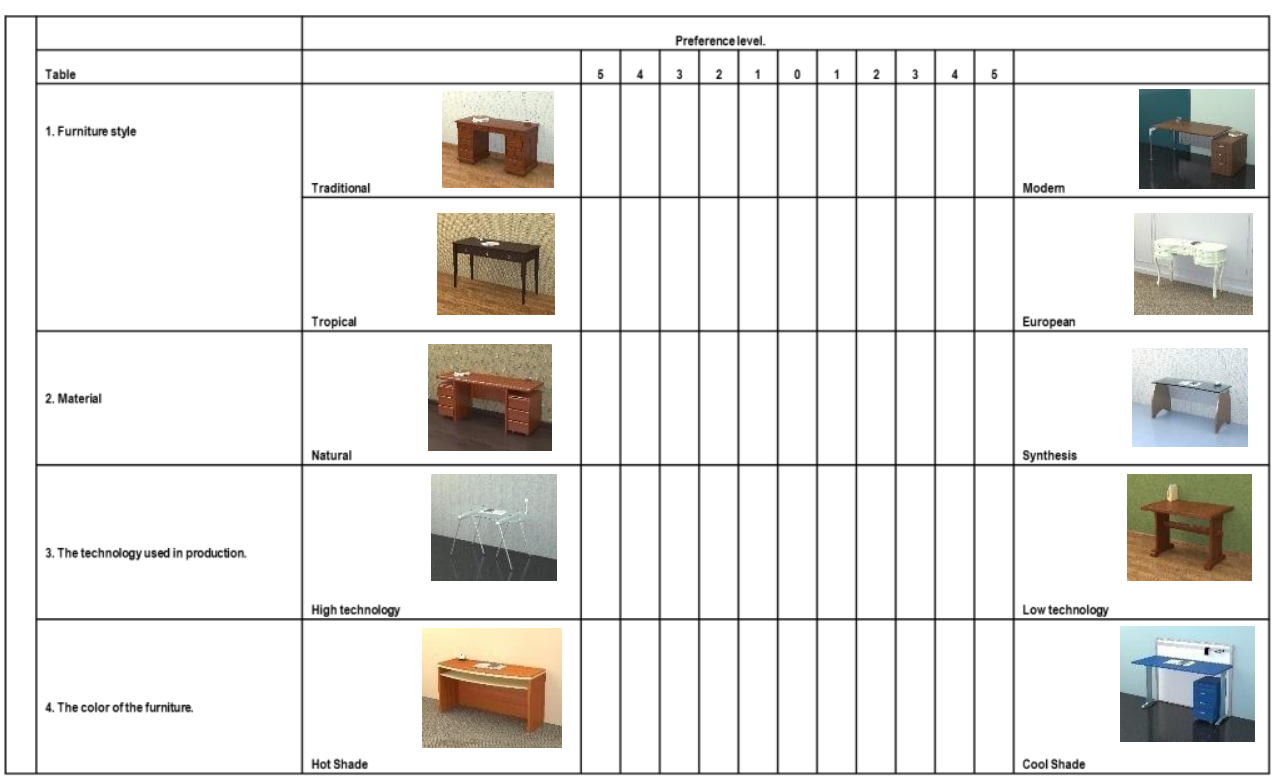

Fig. 1: The questionnaire example. 


\subsection{Findings}

The results of the study on demand for environmentally friendly furniture of the sample. Using finding the mean of the sample demand, it was found that the samples needed Modern furniture style, Western furniture style, used natural materials to produce, has high technology in furniture manufacturing and the colour of the furniture is cool shade. This is an indication of the environmentally friendly furniture that meets the demands of the sample.

\section{Average demand for the furniture style that is environmentally friendly.}

Traditional style
Tropical style
Natural
High technology
Hot shade

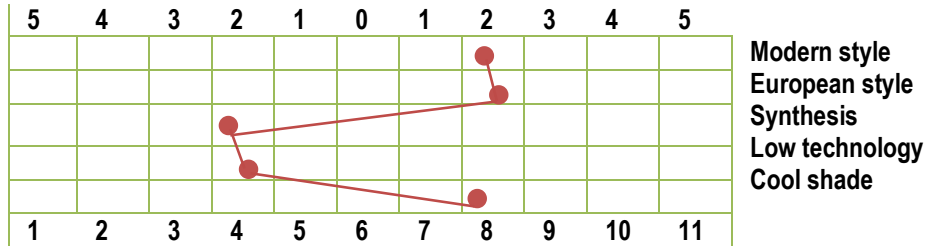

Fig. 2: Average demand for the furniture style that is environmentally friendly.

\section{Analyzing educational levels with the demands of the environmentally friendly furniture characteristics of the sample.}

An analysis of the characteristics of environmentally friendly furniture of the sample. And according to the socio-economic characteristics of the different sample in education. By comparing the mean (Compare mean) and test the relationship in the Linear Regression model, it was found that all education levels tend to demand the environmentally-friendly style of furniture. However, the master's degree group demanded more modern style furniture at the preference level than other education groups. The clarity of the inclination and ability to explain the issues. Of the sample of the sample. Statistically significant level of 95\%, as shown in Table 1.

Table 1. The relationship of educational levels to the needs of the environmentally friendly models of the sample.

\begin{tabular}{l|l|l|l|l|l}
\hline Dependent Variable & $\begin{array}{l}\text { independent } \\
\text { variables }\end{array}$ & $\mathbf{r .}$ & $\mathbf{r}^{2}$ & $\begin{array}{l}\text { B } \\
\text { (Beta) }\end{array}$ & $\begin{array}{l}\mathbf{P} \\
\text { (Sig.) }\end{array}$ \\
\hline Furniture style Traditional / Modern & Education & $.533^{\mathrm{a}}$ & .269 & .533 & $.000^{\mathrm{a}}$ \\
Furniture style Tropical / European & Education & $.847^{\mathrm{a}}$ & .712 & .847 & $.000^{\mathrm{a}}$ \\
Material Natural / synthesis & Education & $.651^{\mathrm{a}}$ & .412 & -.651 & $.000^{\mathrm{a}}$ \\
Technology in process High technology / Low technology & Education & $.646^{\mathrm{a}}$ & .405 & -.646 & $.000^{\mathrm{a}}$ \\
Color Hot shade / Cool shade & Education & $.482^{\mathrm{a}}$ & .216 & .482 & $.000^{\mathrm{a}}$ \\
\hline
\end{tabular}

Analyzing income with the demand of environmentally friendly furniture characteristics of the sample

Consumption of samples depends on many factors. Income is the main factor of socio-economic characteristics of the sample. Highincome individuals also have the opportunity to purchase high-quality products. From the sample of 50 peoples, the group of income was divided into three groups, then the relationship in the form of linear regression (Linear Regression), the income is related to the requirements of the style of furniture is environmentally friendly. Go in the same direction, but there are technical issues in production. The income can describe the style requirements of furniture at a statistically significant level of $95 \%$, as shown in Table 2.

Table 2. Income relationship with the demand for environmentally friendly furniture of the sample.

\begin{tabular}{l|l|l|l|l|l}
\hline Dependent Variable & $\begin{array}{l}\text { independent } \\
\text { variables }\end{array}$ & $\mathbf{r .}$ & $\mathbf{r}^{2}$ & $\begin{array}{l}\mathbf{B} \\
\text { (Beta) }\end{array}$ & $\begin{array}{l}\mathbf{P} \\
\text { (Sig.) }\end{array}$ \\
\hline Furniture style Traditional / Modern & Income & $.470^{\mathrm{a}}$ & .204 & .470 & $.001^{\mathrm{a}}$ \\
Furniture style Tropical / European & Income & $.850^{\mathrm{a}}$ & .716 & .850 & $.000^{\mathrm{a}}$ \\
Material Natural / synthesis & Income & $.693^{\mathrm{a}}$ & .470 & .693 & $.000^{\mathrm{a}}$ \\
Technology in process High technology / Low technology & Income & $.759^{\mathrm{a}}$ & .567 & -.759 & $.000^{\mathrm{a}}$ \\
Color Hot shade / Cool shade & Income & $.462^{\mathrm{a}}$ & .197 & .462 & $.001^{\mathrm{a}}$ \\
\hline
\end{tabular}

It can be seen that the relationships of all independent variables it is related to the demand for materials and technology for the production of every relationship. Therefore, materials used in the manufacture of furniture and technology used in production. It is important for guidelines to design eco-friendly furniture.

\subsection{Discussion \& Analysis}

Environmental friendly furniture design that meets the demands of consumer furniture. The main focus of furniture designers and manufacturer. It will determine the sales very well. The socioeconomic characteristics of the target population determine the demand for furniture. Where potential buyers and decision makers are There is satisfaction in the form of furniture that is environmentally friendly. 
This study the results of some studies that can indicate the socio-economic status of consumers is educational factors, occupation factors and the Incomes factor. (Wyatt-Nichol, Brown, \& Haynes, 2011) For gender and age, the researcher did not present the results. Because the results of the study are not different.

\subsection{The issue of environmentally friendly furniture style.}

The style of furniture that is more environmentally friendly than the traditional one. And western style over east. Which is popular in modern times. Modern furniture is more focused on style. The living style is modern and Western style. The housing project has adopted the style of the house to use more.

\subsection{The issues of material selection used in the production of environmentally friendly furniture.}

Materials used in production. Target groups have demand for environmentally friendly furniture that uses natural materials to produce. As domestic manufacturers turn to more natural materials such as rubberwood, rattan, which are environmentally friendly materials made from natural materials. Feel lively with the residents.

\subsection{The issues of technology used in the production of environmentally friendly furniture.}

Technology in production. Target groups have demand for environmentally friendly furniture that uses high technology. Operators have introduced machine technology to assist in the production of more furniture in the industry. As a result, the price of eco-friendly furniture is not too high and can tell the duration of use of the furniture.

5.4 The issues of colour used in the production of environmentally friendly furniture.

The colour of the furniture is environmentally friendly. The target audience demand for cold coloured furniture. Because the target audience feels comfortable with users and residents.

\section{Conclusions \& Recommendations}

6.1 Design guidelines for environmentally friendly furniture that meets the overall needs of the target audience.

The need for a style of furniture. Between Traditional / Modern style . The majority of modern furniture with a modern style. But the demand is moderate. As shown in the examples section. Modern furniture design patterns.

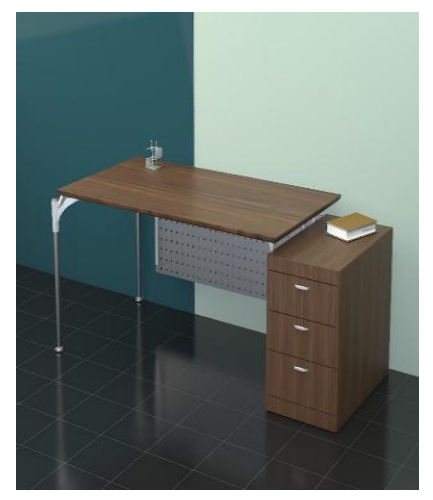

Fig. 3: Design guidelines for Modern-style Environmental Friendly Furniture Design Guidelines of the overall customer segment.

The need for a style of furniture. Between the Tropical / European style. The majority of the demand for European style furniture more than Tropical style but the demand is moderate. As shown in the examples section. European style furniture design.

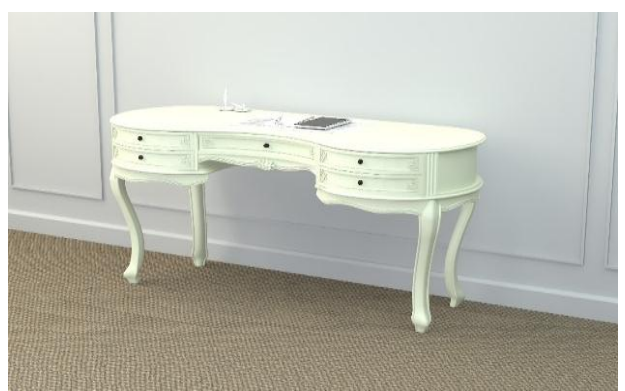

Fig. 4: Design guidelines for Western-style Environmental friendly furniture design of the overall customer segment. 
Requirements for materials used in production. Between natural/synthetic materials. The majority of the demand for furniture made of natural materials. But the demand is moderate. As shown in the examples section. Design furniture made of natural materials.

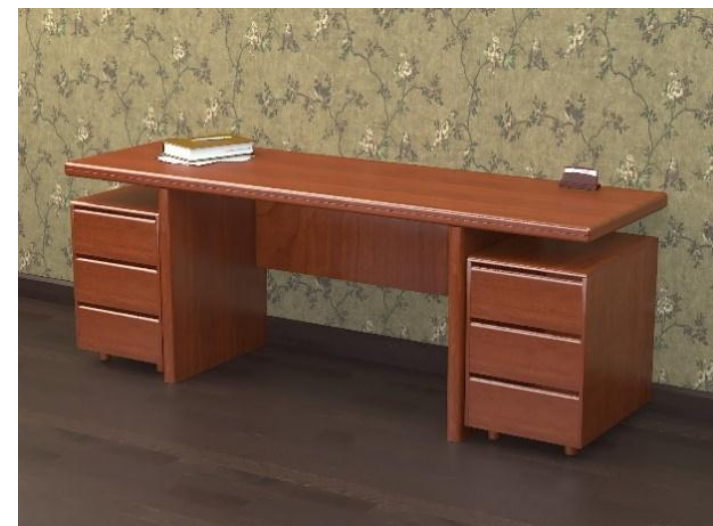

Fig. 5: Design guidelines for Environmental friendly furniture design made from natural materials of the overall customer segment.

The need for the technology used in production. Between High technology/technology Low the majority of furniture needs to use technology to produce high But the demand is moderate. As shown in the examples presented in the section. Furniture design technology in advanced manufacturing.

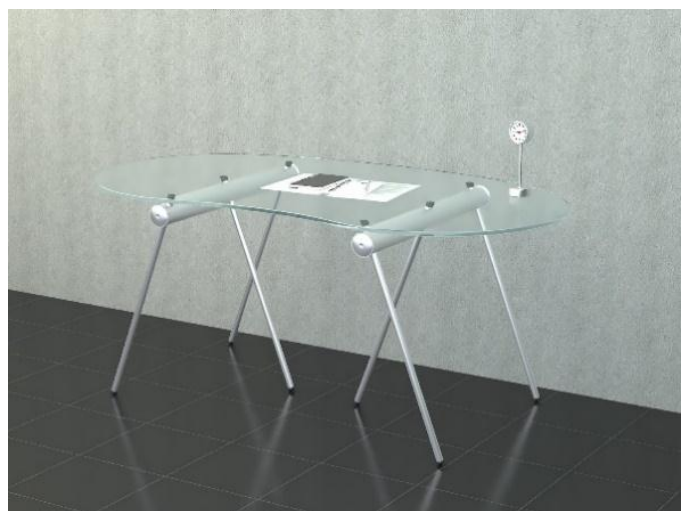

Fig. 6: Design guidelines for Environmental friendly furniture design using high technology of the overall customer segment.

The colour of the furniture during the warm/cool colour group. Most of the furnishings are a cool colour. But the demand is moderate. As shown in the examples section. Furniture design is a cool colour.

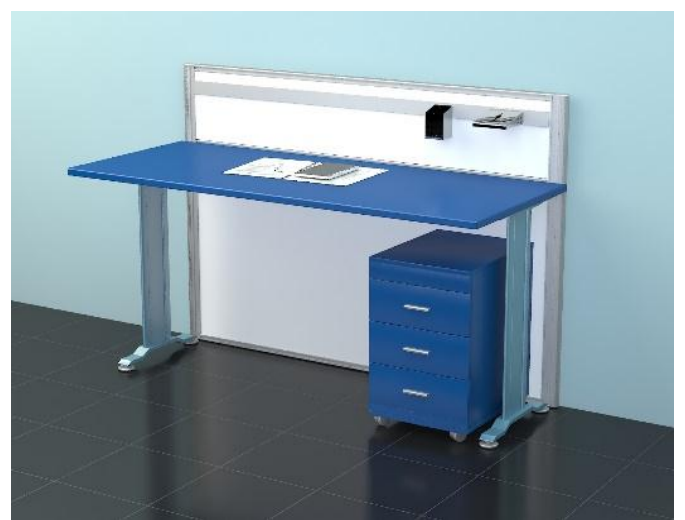

Fig. 7: Design guidelines for Environmental friendly furniture cool colour of the overall customer segment.

The furniture design approach that is based on socio-economic characteristics of the target group.

A group of undergraduate and graduate studies demand style furniture. Modern is moderate. And the furniture made of natural materials is high level. And the furniture used in the production of high technology is moderate. Tone colours of furniture are cool shade is low level. 
A group of undergraduate and graduate studies. Demand style furniture. European is moderate. And the furniture made of natural materials is high level. And the furniture used in the production of high technology is moderate. Tone colours of furniture are cool shade is low level.

The furniture designs are targeted at different occupations for designers to use as guidelines for design.

Group employed demand for furniture in modern style. To a low level, and furniture made from natural materials is moderate. And the furniture used in the production of high technology is high level. The colour of furniture is cool shade is a low level.

\subsection{Applying research results.}

From the study of the differences in the sample with socio-economic factors. Is a key variable but the economic and social conditions cannot be controlled. Design furniture that is environmentally friendly, according to market demand rather difficult. So, Designers should design eco-friendly furniture based on the needs we have to sell first, rather than designing furniture that can be sold for every purpose. The socioeconomic status of the sample is income of sample.

\subsection{Further research.}

In this research may find useful things in design but there are some limitations. The researcher suggested that things to consider and give importance to more completely. In the next research. The reliability of the tool should be tested before use. This research is not able to research all rooms and all types of furniture. Because of the representative of the furniture may not be practical and the furniture has are many types, so next to the research should research all types of furniture to complete more. This research is a study of the demand for environmentally friendly furniture. Using the stimuli, but in fact, the stimuli cannot make the environment of other furniture. Should control the stimuli to cover more furniture

\subsection{Acknowledgements}

The author would like to thank Assoc. Prof. Nopadon Sahachaisaeree Ph.D. and Asst. Prof. Yanin Rugwongwan Ph.D., Faculty of Architecture, King Mongkut's Institute of Technology Ladkrabang, Thailand, and Wichitra Singhirunnusorn Ph.D. for their kind suggestions, guidance, and support to the researcher.

\subsection{References}

Brezet J., a. C. (1997). Ecodesign: A Promising Approach to Sustainable Production and Consumption. Paris: Paris: United Nations Environment Programe.

Consultants of Technology Co., L. (2556, March). 30 years 2526-2556. Retrieved from Consultants of Technology Co., LTD.: http://www.cot.co.th/home/index.php/th/general-news-issue/27-business-economic-management/540-green-consumer.html

Hayles, C. S. (2015). Environmentally sustainable interior design: A snapshot of current supply of and demand for green, sustainable or Faire Trade products for interior design practice. International Journal of Sustainable Built Environment, 4, 100-108. doi:10.1016/j.ijsbe.2015.03.006

Henlen Lewis and John Gertsakis whit Tim Grant, N. M. (2001). Design+Environment: a Global Guide to Designing Greener Goods. UK: Greenleaf Publishing Limited.

Matthew A. Cole, R. (2007). Industrial Activity and the Environment in China: An industry level analysis. 393-408. doi:10.1016/j.chieco.2007.10.003

Ming-Chuan Chiu, C.-H. C. (2012, July). Review of sustainable Product Design from Life Cycle Perspectives. International Journal of Precision Engineering and Manufacturing, 13(7), 1259-1272. doi:10.1007/s12541-012-0169-1

Mohamad T. Araji, S. A. (2013). Realizing the environmental impact of soft materials: Criteria for utilization and design specification. Materials \& Design, $43,560-571$. doi:10.1016/j.matdes.2012.07.053

SMEs. (2014). SMEs High Growth Sectors. Bangkok: SMEs Whitepaper 2014.

Wyatt-Nichol, H., Brown, S., \& Haynes, W. (2011). Social Class and Socioeconomic Status: Relevance and Inclusion in MPA-MPP Programs. Journal of Public Affairs Education, 17(2), 187-208. Retrieved from http://www.jstor.org/stable/23036111 